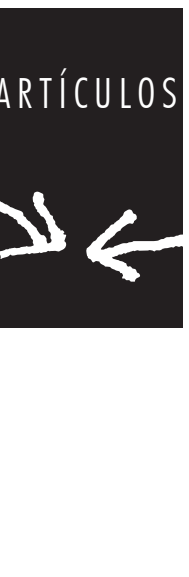

\title{
Desde la asimilación hasta el transnacionalismo: Dinámicas lingüístico-migrałorias y cambios de paradigma en su estudio
}

\section{Eva Gugenberger}

El artículo se propone explorar el desarrollo de las dinámicas migratorias en el siglo XX hasta la actualidad, enfocándose en el impacto lingüístico en los grupos e individuos migrantes. Como puntos de partida me serviré de dos modelos teóricos: la clasificación de Pries, quien distingue como tipos o modelos migratorios la e/inmigración, la migración de retorno y la migración transnacional, predominantes en diferentes épocas de acuerdo con las condiciones migratorias y las distintas concepciones de la sociedad que los sustentan; y -entrelazada con esta clasificación- la tipología de estrategias de aculturación acuñada por Berry: asimilación, separación, marginalización e integración. Analizaré las implicancias lingüísticas de cada uno de estos tres tipos migratorios con atención particular en las redes sociales y el repertorio lingüístico de los migrantes, ilustrándolos mediante ejemplos elegidos. Al final de mi contribución ampliaré la tipología de Berry de acuerdo con las características de los movimientos migratorios recientes y el paradigma actual para su estudio en la sociolingüística.

Palabras claves: lingüística de la migración, modelos de migración, migración transnacional, migración de retorno, españoles, gallegos, portugueses.

From assimilation to transnationalism: linguistic-migratory dynamics and paradigm shifts in their study. The article aims to explore the development of migratory dynamics in the 20th century up to the present, focusing on the linguistic impact on migrant groups and individuals. It is based on two theoretical models: the classification proposed by Pries, who distinguishes between emigration/immigration, return migration and transnational migration as migratory types or models, which are predominant in different periods according to migration conditions and different conceptions of society; and - intertwined with this classification - the typology of acculturation strategies coined by Berry: assimilation, separation, marginalization 
and integration. I will analyze the linguistic implications of each of these three migration types with particular attention given to social networks and the linguistic repertoire of migrants, illustrating them with a selection of examples. At the end of my article, I will expand Berry's typology according to the characteristics of recent migratory movements and the current paradigm for their study in sociolinguistics.

Keywords: linguistics of migration, migration models, transnational migration, return migration, Spanish, Galician, Portuguese.

\section{Introducción: modelos de migración y estrategias de aculturación}

El fenómeno de la migración ha generado diferentes modelos para enfocar y analizar los procesos sociales, culturales y lingüísticos que experimentan los migrantes. Según el sociólogo Ludger Pries, se puede distinguir tres modelos o tipos de migración que prevalecen [pero no son exclusivos] en diferentes épocas: la emigración/ inmigración, la migración de retorno y la migración transnacional o transmigración (Pries 2000: 415-419). ${ }^{1}$

El primero se refiere al migrante que sale de su país para asentarse de forma permanente en la sociedad receptora. Según los sociólogos de la Escuela de Chicago, pioneros de los estudios migratorios en los años 1920 , este modelo va emparejado con el supuesto de que los inmigrantes pasen por un proceso de incorporación que comprende varias fases y que desemboca en su asimilación a la sociedad receptora (Han 2010: 38 y ss.).

Este enfoque de asimilación unilinear fue revisado y ampliado por una perspectiva diversificada propuesta por el psicólogo John Berry (1996). En su tipología parte del concepto de aculturación como hiperónimo que engloba cuatro estrategias aculturativas, según los lazos con la cultura de origen y de acogida: asimilación, separación, integración y marginalización. Estas correlacionan con diferentes configuraciones identitarias.

En un principio, los cuatro tipos constituyen orientaciones o actitudes, a partir de las cuales los migrantes desarrollan diferentes estrategias de aculturación en sus prácticas. Aplicadas a la dimensión lingüística, las cuatro opciones significan lo siguiente (Gugenberger 2007: 32-36, 2018: 189-192, 240-245):

- Asimilación: El migrante muestra una gran disposición de adoptar la lengua/ variedad ${ }^{2}$ receptora a costo de la propia. Se apoya

Lengua y migración / Language and Migration 12:1 (2020) Monográfico, 13-37

Edición impresa: ISSN 1889-5425. Edición en línea: ISSN 2660-7166. @ Universidad de Alcalá 
fuertemente en el modelo de identidad de la sociedad receptora. Al no usar la L1, esta va perdiendo paulatinamente relevancia para su identidad lingüística, hasta que considera solo la L2 como parte de su identidad actual.

- Separación: El migrante prefiere usar su propia lengua sin interés en aprender ni usar la otra. No busca contactos con miembros de la sociedad receptora, más bien prefiere moverse en redes sociales en las que puede hablar la L1. Por lo tanto, la lengua de la sociedad receptora no se vuelve parte integral de la identidad del migrante, siendo su lengua materna la única que siente como "suya” y que reafirma la pertenencia al grupo originario.

- Integración: El migrante tiene interés en saber y hablar las dos lenguas. A fin de poder comunicarse con personas de ambos lados, se empeña en aprender la lengua de la sociedad receptora, al mismo tiempo que quiere mantener la competencia y el uso de su lengua de origen. Con el tiempo va considerando las dos lenguas como parte de su identidad lingüística. Según el contexto comunicativo, emplea una u otra lengua o utiliza ambas alternando entre ellas en la misma interacción (code-switching, language mixing). ${ }^{3}$

- Marginalización/ oscilación: ${ }^{4}$ La oscilación se caracteriza por desorientación, indiferencia e indecisión entre ambas sociedades, muchas veces como reflejo de un conflicto identitario. El migrante tiende a oscilar entre la pertenencia a una o la otra sin sentirse miembro completo de ninguna de las dos. Esta actitud se manifiesta en que tiene poco interés en aprender y usar la nueva lengua, pero tampoco la lengua de origen constituye un alto valor para él que se debe preservar. En la práctica lingüística tiende a acomodarse a la lengua hablada por el interlocutor o oscila entre las dos lenguas sin decidirse por una de ellas. ${ }^{5}$ No siente totalmente "suya" ninguna de las dos lenguas, un fenómeno, que Oksaar (2003: 163) ha denominado "sprachliche Heimatlosigkeit" " $s i n$ hogar lingüístico") y en el que se refleja una "identidad difusa” (Marcia 1989: 161). En general, la oscilación es una fase transitoria, pero también puede perdurar si el migrante no resuelve el conflicto identitario inducido por la migración.

Cabe destacar que todas estas orientaciones o estrategias pueden darse simultáneamente en cualquier época, pero son tipos determinados que prevalecen en distintos períodos, ya que interactúan con las ideologías político-lingüísticas vigentes de los Estados receptores, que se pueden describir con los mismos términos. ${ }^{6}$ Por lo tanto, cada una de estas opciones se refiere tanto a la perspectiva de los migrantes como a la del Estado o la sociedad de acogida. 
El modelo de asimilación, que se dio por sentado durante mucho tiempo en los Estados nacionales, fue puesto en tela de juicio a partir de los años 1960, al paso que las sociedades se volvieron cada vez más multiculturales y plurilingües. En Europa, este proceso fue impulsado por el creciente número de migrantes laborales, los llamados 'trabajadores invitados', los que se desplazaron del sur hacia el centro y norte de Europa. Surgió el discurso de la multiculturalidad, lo que significa que el paradigma nacional y la ideología asimilista iba perdiendo fuerza a favor de una actitud positiva hacia la diversidad cultural. En este nuevo paradigma multicultural se reconocían y se aceptaban las diferencias culturales y lingüísticas. Sin embargo, por multiculturalidad y multilingüismo no se entendía la integración en el sentido de Berry, es decir, que los migrantes mantuviesen rasgos culturales de la sociedad de origen y al mismo tiempo se apropiaran de los de la sociedad anfitriona. Más bien consistía en la mera coexistencia de grupos distintos, de 'minorías', uno al lado del otro, separados y excluídos de la sociedad receptora. Entonces, según la tipología de Berry, la estrategia predominante de aquella época era la separación/segregación, que prevalecía entre los 'trabajadores invitados'. Como su estadía en la sociedad se prevía como un período limitado que se iba a terminar con su pronto regreso al país de origen, estos migrantes corresponden al modelo de migración de retorno, como veremos más adelante.

El tercer modelo, la migración transnacional o transmigración, fue ganando relevancia a partir de los años 1990, al observar que hay un número creciente de migrantes que ya no se pueden describir con base en un modelo dicotómico (sociedad de origen - sociedad receptora). Los transmigrantes se caracterizan por movimientos circulares entre el país de origen y de residencia o incluso otros lugares más, construyendo así espacios transfronterizos.

En los siguientes apartados abordaré cada uno de los tres modelos de migración, señalando las diferentes concepciones de la sociedad que los sustentan. Delinearé las principales diferencias con respecto a su impacto lingüístico, haciendo hincapié en el desarrollo de las redes sociales y del repertorio lingüístico de los migrantes, así como su interrelación con la dimensión identitaria y las estrategias aculturativas basadas en la tipología de Berry. Al final, ampliaré esta tipología de acuerdo con las características de los movimientos migratorios recientes y el paradigma actual para su estudio en la sociolingüística. Los ejemplos que voy a presentar para cada modelo, casos de diferentes migrantes iberorrománicos, los utilizo únicamente de manera ilustrativa y con el propósito de dar soporte empírico a la parte conceptual de mi contribución. Todos los ejemplos son tomados de estudios cualitativos sobre la base de entrevistas semiestructuradas guiadas por un cuestionario o guía de entrevista. ${ }^{7}$

Lengua y migración / Language and Migration 12:1 (2020) Monográfico, 13-37

Edición impresa: ISSN 1889-5425. Edición en línea: ISSN 2660-7166. @ Universidad de Alcalá 


\section{El modelo de emigración / inmigración}

Como ya se ha mencionado, este modelo consiste en que los migrantes se desplazan de su región de origen a otro país en el cual se instalan perdurablemente, por tanto, se refiere a una forma de migración unidireccional. Es característico de los flujos migratorios del siglo XIX y la primera mitad del siglo XX dentro de Europa y desde Europa hacia América y Australia.

Estos movimientos migratorios coinciden con el período del paradigma nacional que surgió con la creación del Estado-Nación en el siglo XVIII (Middel/ Middel 1998). El modelo de nación, al que subyace el conocido ideologema 'una nación - una lengua - un Estado', es decir, una concepción monolingüe de la sociedad, también fue adoptado por los Estados latinoamericanos fundados después de la Independencia. En ellos, el español como lengua nacional única debía contribuir a la construcción de naciones aún poco consolidadas y a crear una identidad lingüística nacional. Por tanto, los Estados procuraron la asimilación de los inmigrantes.

Los países de destino de la gran cantidad de europeos que emigraron a América Latina fueron principalmente Cuba, Argentina y Brasil. En Argentina, que quiero tomar como ejemplo, destacaban Italia y España entre los países de origen -constituyendo los gallegos el mayor grupo entre los migrantes españoles-, seguidos por muchos otros países (como Polonia, Rusia, Francia, Turquía, Alemania, Austria [Imperio Austrohúngaro], etc.).

Aunque entre ellos prevalecía el tipo e/inmigrante, cabe mencionar que también en aquella época había migrantes que retornaron a su país de origen o que iban y venían como los llamados 'migrantes golondrinas', que cruzaban cada año el Atlántico para trabajar en la cosecha de distintos cultivos. Los que se asentaron en zonas rurales, resistieron más a la asimilación y solían mantener sus lenguas a través de varias generaciones, mientras que los que se establecieron en las grandes urbes como Buenos Aires, sufrieron un desplazamiento lingüístico más acelerado.

Aparte de la ideología lingüística estatal, asumida muchas veces por los migrantes mismos, esto se debe a varios factores:

- En la ciudad, migrantes de distintos orígenes solían vivir puerta a puerta en los llamados conventillos. Generalmente trabajaban en el comercio minorista, como artesanos o en el sector de servicios. Esto implicaba que las redes sociales consistían de relaciones múltiples, que incluían miembros de la sociedad receptora y migrantes de otras lenguas. Es decir, había un cambio de la 
estructura de las redes sociales (Milroy 1980), desde redes cerradas, caracterizadas por multiplejidad y alta densidad, ${ }^{8}$ típicas de la vida en las zonas rurales de las que provenía la gran mayoría de los migrantes, hacia redes más abiertas, de menor complejidad y densidad, en las que se usaba el español como lingua franca.

- Otro factor que distingue los migrantes de aquella época de los de hoy en día y que actuaba en contra del mantenimiento de la lengua de origen, es la poca posibilidad de retorno y contacto continuo con el país de origen debido a la distancia geográfica y la escasez de recursos económicos y medios de transporte.

- Además, el gran deseo de progresar económica y socialmente promovía la disposición a la asimilación lingüística, reclamada por el Estado receptor.

- Esta disposición era especialmente alta en el caso de los gallegos, que he estudiado con mayor detalle (Gugenberger 2007, 2018), debido a la estigmatización que sufrían. Eran tildados como brutos e ignorantes, y su lengua, el gallego, era considerado un 'mal castellano', debido a la proximidad lingüística entre ambos idiomas. En su voluntad de castellanizarse no se refleja solo la ideología del Estado argentino, sino también la del Estado español en aquella época. Debido a la situación diglósica existente en Galicia, en la que el gallego se encontraba en una posición de desventaja frente al idioma oficial, el castellano, al llegar a Argentina los migrantes ya habían asumido una actitud negativa respecto a la conservación de su lengua materna, el gallego.

En las entrevistas con los migrantes gallegos en Buenos Aires ${ }^{9}$ se pone de manifiesto el proceso de asimilación al castellano, empezando en los espacios públicos hasta alcanzar el ámbito familiar. Como razón principal se menciona la necesidad de tener una lengua de comunicación en común en una sociedad multiétnica y multilingüe, una característica de la Argentina en aquella época debido a la masiva inmigración. Así por ejemplo, Paula, ${ }^{10}$ que llegó en los años 1930, indica:

[...] y después al venir aquí no podías hablar gallego porque, viste, que acá hay tanta raza de gente que vos vas al almacén uno es italiano, otro es de otro ... no podés hablar gallego, y no hablo yo mucho gallego, no, no hablo mucho. Hablo con quien sabe hablar gallego o quiere hablar gallego, me gusta hablar el gallego, pero más bien me tira el castellano porque sho te digo la verdá, ya estoy tan acostumbrada acá.

Otra razón mencionada a menudo por los entrevistados que les motivó a dejar de hablar gallego es la estigmatización sufrida. En el 
siguiente extracto de la entrevista con Mauricio se mezclan sentimientos de inferioridad, de vergüenza y el deseo de adoptar la manera de hablar de los miembros de la sociedad receptora:

$\mathrm{E}^{11}$ - Entonces así se reunían los gallegos. ¿Ahí se hablaba gallego o no?

M- No, entre nosotros gallego, sí, entre nosotros gallego.

E- Con su señora, ¿en qué lengua hablaba?

M- Gallego, en la casa, castellano después. Castellano, sí.

E- Cuando estaba enamorando a su señora, ¿le hablaba en gallego o en castellano?

M- Hablábamos chapurreado, hablábamos de todo, chapurreado sí. Chapurreado quiere decir de todo, vio: castellano, gallego. Sí. Acá más bien nosotros cuando estábamos afuera, aquí en las fiestas y eso, teníamos vergüenza hablar gallego, casi, entonces tirábamos a hablar castellano.

E- ¿Vergüenza por qué?

M- No sé, porque nos considerábamos atrasados, vio. Nos considerábamos atrasados, por eso mismo. Era un poco de orgullo, va, en ese caso. Orgullo de ser como la gente de acá o hablar como los de acá. Eso es.

E- Sí, me han hablado de esas cosas.

M- Ah, le han hablado. Sí, teníamos ese orgullo de ser como la gente de acá, de alternar, no. Pero entre nosotros hablábamos gallego. [...] Y acá era más usual hablar castellano porque usted se enfrentaba a la gente, de otras condiciones, de otros estilos. Eso es. Y uno de acá no le comprende el gallego, por ejemplo, tiene que hablar castellano, o tenía, va. Eso es.

Asimismo, para Yolanda, dejar de hablar gallego y hablar como los otros constituía una parte necesaria de la adaptación. Cuenta que desde su llegada a Buenos Aires ella ha evitado hablar gallego para no quedar mal. Se acuerda de las palabras de su cuñada: "lo primero que me dijo mi cuñada cuando llegué acá fue '¡No hables en gallego ni una sola palabra!'” Igual que Yolanda, otros informantes también indican que eran los mismos familiares, que vivían desde hacía tiempo en Buenos Aires, quienes incentivaban -e incluso obligaban- a los recién llegados a hablar castellano.

$\mathrm{Al}$ asumir el estereotipo del 'gallego bruto', los migrantes mismos se consideraban brutos, transmitiendo este estigma a su lengua, de manera que algunos preferían callarse para no tener que mostrar su origen cultural lingüístico, como expresa Olga:

Y sho pensaba de los gashegos que los gashegos en la emigración solo vino ... nada más que vinieron los brutos, no tenían la culpa, o sea que nosotros no teníamos la culpa de ser brutos, fue lo que nos dieron, si no nos dieron educación, no nos enseñaron otra cosa, pues ¿qué éramos? Brutos, era la fuerza bruta, nada más, y aquí a los trabajos más brutos también, éramos brutos en hablar, en expresarnos [...].

Lengua y migración / Language and Migration 12:1 (2020) Monográfico, 13-37 Edición impresa: ISSN 1889-5425. Edición en línea: ISSN 2660-7166. @ Universidad de Alcalá 
Sha te digo sho cuando vine, sho iba en el colectivo o en en tranvía lo que fuera y sho no abría la boca, no quería que se enterara nadie del idioma, del acento mío, me daba vergüenza, sho no abría la boca [...].

Al no usar una lengua durante mucho tiempo, se ve afectado el repertorio lingǘstico del que dispone el hablante. Por lo tanto, en el caso de los gallegos, la mayoría ha perdido la habilidad de hablar fluidamente el gallego, quedando su competencia activa parcial (en distinto grado) o incluso nula, aunque todavía lo comprende.

Sin embargo, también hay migrantes que han conservado el gallego y lo usan en relaciones con coterráneos -por lo general, alternando o mezclándolo con el castellano en prácticas bilingües- $y$, por tanto, corresponden al tipo integracionista. No obstante, la lengua de comunicación principal dentro de la red étnica suele ser el castellano. Por lo tanto, si se considera la asimilación como el desplazamiento del gallego a favor del castellano como lengua habitual, este proceso está bastante avanzado. Pero si se toma en cuenta que Galicia es una sociedad bilingüe y que la mayor parte de los entrevistados, como ellos mismos indican, ya habían adquirido el castellano -si bien en diferentes grados de dominio- en su variante regional de Galicia, hay que considerar también el contacto dialectal entre la variedad peninsular y la rioplatense del castellano. A este respecto, es decir, en cuanto al modo de hablar español se nota que muchos migrantes no se han asimilado totalmente a la variedad argentina, más bien conjuegan rasgos de ambos dialectos creando un modo de habla interdialectal, que es su manera de marcar su identidad lingüística integrativa. Esto ilustra, por ejemplo, el caso de Beatriz. Por un lado, ella mantiene la distinción entre la fricativa interdental / $\theta /$ y la alveolar $/ \mathrm{s} /$ y casi nunca aspira la /s/ implosiva. Por otro lado, muestra una tendencia al žeísmo, habla con voseo y utiliza algunas formas léxicas del español argentino. Veremos un extracto de la entrevista con ella: ${ }^{12}$

Acá esha me shama y me dice: "vos sabés algo de Amancio, que esto, que lo otro, que está enfermo, hablastes con tu papá”, y esto y lo otro y entonces es eso la ... saber ... porque si vos te quedas acá encerrado no sabés como está tu ... tu colectividad en sí, no sabés, no te ... no sabés qué pasa. Hoy sha sabés que pasa porque está el canal de España, o de Galicia para el mundo y te enganchás, pero no te enganchás con las familias de acá que realmente es lo que vos tenés que rozar, con quien te ... TES que hablar, con quien puedes estar y hay veces que te .... sho por eso a esos XANTARES me encanta ir, aparte escuchas tu música, escuchás tus cosas, tu ... tu ... tu todo.

Las siguientes generaciones, en cambio, hablan la variedad rioplatense con todas sus características. Aparte del castellano, sobre todo las personas más jóvenes, suelen tener conocimientos de otras lenguas como el 
inglés, pero muy pocas disponen de una competencia activa del gallego, ya que, por lo general, los migrantes no transmitieron su lengua materna a sus hijos por las razones expuestas.

En definitiva, lo que se observa (con algunas excepciones) entre los gallegos en Buenos Aires es -como en muchos otros casos del tipo e/inmigración en la época del paradigma nacional- la pérdida de la lengua de origen a través de las generaciones y el desplazamiento a la lengua de la sociedad receptora. ${ }^{13}$

\section{El modelo de la migración de retorno}

A partir de la década de los sesenta del siglo pasado se inició otra fase de migración, que dio origen al paradigma multicultural. Este va de la mano del modelo de migración de retorno, que caracteriza a los migrantes laborales, que llegaron con contratos temporales (generalmente como obreros industriales), y que, por tanto, supone una estadía limitada en el país anfitrión.

Cabe señalar que el concepto de retorno, según Mar-Molinero (2018), permite varias lecturas:

- el retorno 'físico real', que puede ser permanente o temporal

- el retorno 'virtual' a través de enlaces mediáticos

- el retorno 'aspiracional' o 'imaginario', es decir el sueño de que un día el migrante 'volverá a casa'

Si bien muchos migrantes de aquella época realmente retornaron a sus países de origen, la estadía resultó muchas veces más duradera de lo esperado o incluso permanente. Pero aun así, los migrantes seguían teniendo en mente el 'mito del retorno', lo que contribuyó a su poca motivación de adquirir la lengua del país anfitrión.

Su orientación de separación se manifiesta en la composición de sus redes sociales que abarcaban:

- relaciones intensas con coterráneos, tanto en el país receptor como en el de origen

- contactos con otros migrantes (compañeros de trabajo y otros)

- pero contactos muy limitados con miembros de la sociedad de acogida

En las fábricas donde trabajaban había a menudo una concentración de obreros del mismo país. Asimismo, en el tiempo libre los migrantes 
del mismo origen solían quedarse entre ellos. Vivían en una especie de 'islas' culturales, como observan Bierbach y Birken-Silverman (2003: 91-92) en la primera generación de migrantes de Italia y España en Alemania. Estas se caracterizaban por la conservación de sus propias costumbres y el uso preferido de la lengua materna, de modo que una buena parte de ellos solo alcanzó un nivel reducido del alemán.

Lo mismo destaca Estévez Grossi (2018) para el caso de los migrantes laborales gallegos en Hannover. En su estudio descubre que la mayoría de ellos adoptó la estrategia de separación, aunque -en menor gradotambién ha podido identificar orientaciones integrativas y formas mixtas. Como constata la autora (2018: 10), el Estado alemán tampoco tomó medidas para integrar a los migrantes laborales. Al considerarlos una mera reserva de mano de obra temporal cuya permanencia estaba prevista solo para un período limitado, las autoridades alemanas adoptaban una actitud indiferente respecto al aprendizaje del alemán. Asimismo, el Estado español también fomentó la separación, al establecer una serie de instituciones de asistencia para los migrantes con el fin de atarlos a la patria y ejercer control sobre ellos, asegurando de esta manera que permaneciesen entre sí y no tuviesen demasiado contacto con la sociedad local (Muñoz Sánchez 2012: 33-36; citado en Estévez Grossi 2018: 10).

Aparte de los españoles e italianos, un grupo significativo entre los migrantes laborales de lenguas románicas en Alemania lo constituyen los portugueses. Por tanto, a manera de ilustrar este tipo de migración, quiero presentar el caso de Inês y Manuel, un matrimonio de origen portugués que vive en Fráncfort del Meno. ${ }^{14}$

Al llegar en los años 1970 a Alemania, motivados por un contrato temporal que Manuel consiguió en una fábrica, al principio no pensaban instalarse permanentemente como señala Inês: "A gente pensava só vir algum tempo e depois regressar. E como não tínhamos na cabeça a ideia de ficarmos aqui, a gente não tentou aprender o alemão e foi um grande erro que fizemos".

Aunque se han quedado en Alemania hasta ahora, Inês afirma respecto a su marido, que su cabeza sigue estando en Portugal. Por lo tanto, él nunca ha mostrado mayor interés en aprender alemán. Solo ha adquirido competencias de carácter limitado, las que, no obstante, le sirven para comunicarse de forma básica si la situación lo requiere. En cambio, Inês sí se ha empeñado en aprender alemán, así que hoy es capaz de comunicarse con soltura (sobre cualquier tema, como ella afirma) de forma oral. En cambio, considera bastante reducida su destreza en la escritura. Entonces, los repertorios lingüísticos de Inês y Manuel comprenden el portugués, el alemán -aunque en muy distinto grado-y además algo de español e italiano, adquirido en contactos con otros migrantes. ${ }^{15}$

Lengua y migración / Language and Migration 12:1 (2020) Monográfico, 13-37 Edición impresa: ISSN 1889-5425. Edición en línea: ISSN 2660-7166. @ Universidad de Alcalá 
Es obvio que el repertorio se desenvuelve en la práctica social, de acuerdo con la composición de las redes sociales y los usos lingüísticos de los hablantes. La red social de Manuel, desde el principio hasta ahora, ha comprendido principalmente relaciones con personas de habla portuguesa, tanto en el ámbito laboral como en el privado (tiene cinco hermanos en Fráncfort con los que se reúne con frecuencia).

En cambio, Inês fue ampliando su red social mediante relaciones en las que emplea el alemán: sobre todo en su trabajo (es mujer de limpieza en casas privadas) y en el contacto con instituciones (el colegio de sus hijos, trámites con autoridades públicas, etc.).

Además, la red familiar también se ha reconfigurado y vuelto bilingüe por sus dos hijos crecidos en Alemania; ambos tienen novias alemanas. Por tanto, la selección de lenguas en el seno familiar depende de la situación comunicativa: Si las novias están presentes, se habla alemán. (Inês cuenta que su marido suele retirarse al dormitorio en estas ocasiones, ya que le cuesta comunicarse con ellas por su poco dominio del alemán.) Pero si Inês está sola con sus hijos, insiste en hablar portugués con ellos, si bien puede aparecer alguna que otra palabra alemana.

La selección de lenguas, en el primer caso, reside en la función instrumental que cumple el alemán en la conversación con las interlocutoras alemanas, conjuntamente con el deseo de Inês de participar en la vida de sus hijos. En el segundo caso, se motiva por la función identitaria que el portugués desempeña para Inês. Esto se revela en su convicción de que es muy importante transmitir su lengua materna a los hijos, y al destacar el vínculo entre el portugués, que califica como "a nossa língua”, y su pertenencia a su comunidad de origen: "A gente é portuguesa, pois será sempre a nossa língua mais importante.”

En cuanto a su manera de hablar cabe mencionar que suele insertar palabras alemanas en el portugués. Así, por ejemplo, en la entrevista utiliza Zecke (port. 'carrapato', esp. 'garrapata'), Stenerberater (port. 'consultor fiscal', esp. 'asesor fiscal'), kulturelles Zentrum ('centro cultural') y, en el siguiente enunciado, Pharmazie (port. 'farmácia', esp. 'farmacia'), promoviert (port. 'faz o doutoramento', esp. 'hace el doctorado') y Doktorarbeit (port. 'tese de doutoramento', esp. 'tesis de doctorado'). "O mais velho estudou Pharmazie ... eh ... promoveu ... promo ... promoviert ... está a escrever o Doktorarbeit." Al buscar la palabra promovieren en portugués, primero utiliza promoveu, que en portugués tiene otro significado, después recurre a la forma alemana.

Ella es consciente de esta práctica bilingüe, incluso afirma que hay palabras que ni siquiera sabe en portugués, no sabe traducirlas (por lo menos, están disponibles más facilmente en alemán). Las formas alemanas cumplen la función de indexicalidad de segundo orden (en el sentido de Silverstein 2003: 217), es decir, a Inês le parecen más adecuadas, ya 
que las vincula con el contexto sociodemográfico en el que está viviendo. Por medio de ellas se posiciona identitariamente, construye una identidad integrativa bilingüe, que es fruto de su vida en la migración.

Inês percibe y reconoce que su identidad ya se ha transformado de cierto modo al estar tanto tiempo en Alemania. Esto se nota por ejemplo -a nivel sociocultural- en haber adoptado algunos valores de la sociedad alemana, de lo que se dio cuenta durante una visita en Portugal: "ja temos outra mentalidade, a gente ... irrita-se. Revolta-se contra a mentalidade portuguesa, contra os portugueses". Al distanciarse de 'los portugueses', en este enunciado Inês redefine su posición frente a su grupo de origen, construyendo una nueva identidad que es fruto de su experiencia migratoria.

A nivel lingüístico -siguiendo a Le Page y Tabourt-Keller (1985) que sostienen que hablar significa realizar actos identitarios- la identidad integrativa de Inês se manifiesta en su selección de lenguas según el contexto social y, en su modo de hablar portugués, al servirse de alternancias, sobre todo palabras propias de su mundo vivencial en Alemania.

Al retomar el concepto de retorno, se puede decir, que en el caso de Manuel el retorno es

- virtual (lo que muestra por ejemplo su consumo mediático),

- aspiracional, ya que, según él, solo está esperando su jubilación para volver a Portugal,

- y real, de momento aún por temporadas, pero en el futuro tal vez de carácter perdurable.

En cambio, Inês no tiene en mente retornar permanentemente. Quiere quedarse en Fráncfort para estar cerca de sus hijos y porque se siente integrada en la sociedad alemana, o pasar una temporada del año aquí y otra allá.

En definitiva, este ejemplo demuestra que, dentro del marco del mismo modelo de migración -en este caso de retorno- incluso los miembros de la misma familia pueden diferir considerablemente respecto al desarrollo del repertorio y uso lingüísticos, correlacionado con las distintas estrategias aculturativas e identitarias. Manuel representa la estrategia de separación, reflejada en las características descritas arriba, entre otras, en su uso preferido del portugués, sus relaciones sociales mayormente intraétnicas y su fuerte deseo de retornar a su tierra. En cambio, en el caso de Inês, su deseo de permanecer en Alemania ha hecho avanzar el proceso de integración social y sociolingüística. Ha construido una red social multiforme que comprende contactos frecuentes con personas tanto de origen portugués como alemán, ha integrado sus diferentes mundos vivenciales y lingüísticos, desarrollando

Lengua y migración / Language and Migration 12:1 (2020) Monográfico, 13-37

Edición impresa: ISSN 1889-5425. Edición en línea: ISSN 2660-7166. @ Universidad de Alcalá 
una identidad integrativa, lo que se manifiesta en que conserva su lengua materna al tiempo que se ha apropiado del alemán, empleando ambas lenguas de manera flexible en su vida diaria.

Además, no descarta la idea de convertirse en una transmigrante en el futuro que circule entre Portugal y Alemania. Si fuese así, sería un ejemplo de lo que sostienen Glick Schiller, Bach y Szanton Blanc (1995: 48), a saber, que la transición de una forma de migración a la otra puede ser un proceso gradual. Esto nos lleva al tercer modelo de migración que se tratará en el siguiente apartado.

\section{El modelo de la migración transnacional}

En las últimas décadas se viene observando que el retorno muchas veces se vuelve habitual, un viaje circular continuo. Los itinerarios migratorios ya no son uni, sino bi o incluso multidireccionales, es decir no terminan en un lugar, sino que continúan a otros países. Los migrantes suelen vivir entre más de una localidad o vincularse a más de un sitio material o simbólicamente. Estas nuevas dinámicas han dado lugar al concepto de migración transnacional, con el fin de enfocar los complejos entramados sociales y los espacios transfronterizos que los migrantes crean mediante su práctica vivencial.

La vida diaria de los transmigrantes se caracteriza por múltiples y constantes interconexiones a través de fronteras internacionales. Están involucrados en actividades tanto en la sociedad donde residen como en la de origen, como señalan Glick Schiller, Bach y Szanton Blanc, pioneras del enfoque transnacional:

Transmigrants are immigrants whose daily lives depend on multiple and constant interconnections across international borders and whose public identities are configured in relationship to more than one nation-state (...). They are not sojourners because they settle and become incorporated in the economy and political institutions, localities, and patterns of daily life of the country in which they reside. However, at the very same time, they are engaged elsewhere in the sense that they maintain connections, build institutions, conduct transactions, and influence local and national events in the countries from which they emigrated (Glick Schiller/ Basch/ Szanton Blanc 1995: 48).

De este modo, los migrantes ya no están incorporados en un solo sistema de referencia monolocal, sino que integran elementos de ambas regiones y sociedades para formar algo propio y nuevo (Pries 2008: 62). De esta manera, están construyendo identidades híbridas con referencias múltiples, lo que se refleja en su repertorio pluricultural y plurilingüe (Lüdi 2003, Bossong 2009).

Lengua y migración / Language and Migration 12:1 (2020) Monográfico, 13-37 Edición impresa: ISSN 1889-5425. Edición en línea: ISSN 2660-7166. @ Universidad de Alcalá 
Cabe recordar que también el concepto de integración ya encierra la idea de generar algo nuevo. Así, por ejemplo, el psicógolo GarzaGuerrero, en el año 1974, ya hablaba de la creación de una nueva identidad del migrante que va más allá de una identidad bicultural en términos de una mera adición (1974: 422-425). Sin embargo, los conceptos acuñados en los discursos científicos más recientes, como hibridación, ${ }^{16}$ transculturalidad y transnacionalismo, aparte de subrayar la emergencia de algo nuevo, quieren superar modelos binarios, al poner énfasis en la anulación de los polos opuestos y entidades fijas con límites nítidos (naciones, culturas, lenguas) y en la transgresión de fronteras, enfocando los espacios intermedios y transfronterizos.

En relación al concepto de hibridación, cabe señalar que el término no es nuevo, tiene una larga trayectoria tanto en las ciencias humanas y naturales como en la lingüística. ${ }^{17}$ Pero a la luz de las teorías posmodernas y poscoloniales, la noción de hibridación -principalmente por la repercusión de las obras de Homi Bhabha (1994) y García Canclini (1990)- ha adquirido nuevos valores, convirtiéndose en un concepto clave en el análisis de procesos de contacto y mezcla entre diferentes culturas, literaturas, estilos de arte, lenguas, etc. ${ }^{18}$ Los defensores del concepto se dirigen contra dos posturas que han influenciado durante mucho tiempo las concepciones de cultura: por un lado, contra la modelación de cultura como un sistema monolítico cerrado y, por otro, contra el supuesto de que una cultura -ignorando la formación de ella en procesos de contacto y mezcla- sea algo puro que deba conservarse en esta 'pureza', es decir, contra una postura purista según la cual las adopciones de otras culturas se tildan como corrupción, deteriorio o bastardización. El concepto de hibridación, tal cual como se utiliza en los discursos poscoloniales, incluye -al contrario de su historia cultural ${ }^{19}$ - una postura ideológico-evaluativa que valora positivamente el entrelace de dos culturas. Cabe destacar que lo nuevo del concepto no es el fenómeno como tal, puesto que siempre ha habido procesos de hibridación entre culturas, pero lo que constituye lo innovativo es el cambio de perspectiva. El interés ya no se centra en los sistemas como polos opuestos, sino más bien en los espacios intermedios, en el 'tercer espacio', para utilizar la metáfora de Bhabha (1997: 124), en el cual el más allá es posible. Superando la concepción de cultura como entidad estática, se considera la cultura como un proceso dinámico de negociación. Además, la noción de hibridación abarca la idea de emancipación social, ya que los actores ponen en tela de juicio concepciones transmitidas de homogeneidad cultural, purismo, nación y cultura nacional, reclamando el reconocimiento de la diversidad (Erfurt 2005: 31).

$\mathrm{Al}$ igual que la hibridación, la transmigración tampoco es un fenómeno totalmente nuevo. Más bien es una forma más intensa y compleja

Lengua y migración / Language and Migration 12:1 (2020) Monográfico, 13-37

Edición impresa: ISSN 1889-5425. Edición en línea: ISSN 2660-7166. @ Universidad de Alcalá 
de un tipo de migración ya existente, que es un producto del mundo altamente interconectado que la creciente movilidad y la tecnología moderna han creado (Gugenberger/ Mar-Molinero 2018: 8).

El modelo de migración transnacional y las conexiones transfronterizas han generado sociedades transculturales y comunidades transnacionales. Las redes sociales adquieren un nuevo carácter, aunque es preciso destacar, que lo novedoso de la transmigración no es el enlace con la sociedad de origen, que, por lo general, también existía anteriormente, sino, es "la diversidad y densidad de las redes sociales, así como su frecuencia, facilitada por las innovaciones en medios de transporte y comunicaciones globales", como indican Andrade-Eeckhoff y Silva Ávalos (2004: 63).

Estas redes pueden desplegarse entre más de dos localidades, permiten moverse de manera contínua, física y virtualmente, entre distintos mundos y regiones geográficas. A través de los medios digitales los transmigrantes están en contacto permanente con familiares y amistades, donde quiera que estos estén, en el país de origen, de residencia o en otra parte del mundo.

Para ilustrar esto, veremos el caso de Rocío, una mujer joven de origen gallego, estudiado por Griszbacher (2018). ${ }^{20}$ Rocío fue a Alemania a estudiar un año en Leipzig, regresó a Galicia por dos años, volvió a Alemania, a Múnich, donde trabajó un año y medio, y ahora vive en Irlanda donde trabaja en la empresa de Google. Su red social comprende relaciones con personas en los tres países, con las que mantiene contacto frecuente gracias a las tecnologías de comunicación modernas. Además, se comunica diariamente con su novio que es francés y que actualmente vive en Holanda. Este ejemplo demuestra muy bien que, debido a la transmigración, la composición de las redes sociales se ha vuelto más compleja.

En el plano lingüístico, la creciente movilidad y los vínculos múltiples llevan a un plurilingüismo dinámico característico de las sociedades modernas. Las nuevas dinámicas lingüísticas han evidenciado más que nunca que las concepciones tradicionales sobre la 'lengua' y la 'competencia lingüística' han quedado obsoletas y ya no sirven para el análisis de las habilidades y usos lingüísticos de los grupos heterogéneos surgidos.

De manera similar a la dinamización de la noción de cultura en las ciencias culturales, la concepción de lenguas como entidades monolíticas fue descartada a favor de una visión más dinámica, que ya no parte de una lengua de forma separada, sino de la heterogeneidad y la hibridación para el análisis de la práctica lingüística y discursiva (Erfurt 2003: 25). Al adoptar una 'postura hibridista' o 'translingüe', como la he denominado (Gugenberger 2010b, 2018: 194), ${ }^{21}$ que se dirige contra una ideología purista, la mezcla de lenguas ya no se evalúa como expresión de un déficit lingüístico, como incapacidad del hablante de separar las lenguas. Además, la perspectiva de la hibridación contrasta claramente con el anti- 
guo modelo del individuo bilingüe 'ideal' en el sentido de un 'monolingüe doble' cuyo dominio de ambas lenguas es casi 'perfecto' y según el cual cualquier influencia de la otra lengua en el habla se categoriza como error o interferencia, como contaminación o violación contra el sistema.

La superación de la perspectiva monolingüe y del sistema lingüístico como foco del análisis ha dado lugar a enfoques centrados en el hablante multilingüe. Ya no se parte de la fijación espacial de los seres humanos y las lenguas, sino de recursos lingüísticos flexibles, de los que se sirven los hablantes multilingües y los que se emplean en contextos reales socioculturales, históricos y políticos (Blommaert 2010: 5). En sus prácticas translingües, los hablantes como actores creativos combinan diferentes elementos, crean formas nuevas, respondiendo así a la dinámica lingüística en una sociedad plurilingüe.

Los contextos de movilidad, diversidad y flexibilidad favorecen que los transmigrantes desarrollen un repertorio plurilingüe complejo. Por eso, este concepto, que ya fue propuesto por Gumperz en los años sesenta del siglo pasado $(1964,1982)$ y que ya he mencionado arriba, ha encontrado gran repercusión en la sociolingüística actual. Al contrario de las nociones tradicionales de 'lengua' y 'competencia lingüística', el concepto de repertorio lingǘstico parte del conjunto de los recursos lingüístico-comunicativos del que dispone una persona y los que emplea de manera flexible en contextos diferentes en sus interacciones diarias (Busch 2013: 21). Busch concibe el repertorio lingüístico como un heteroglósico espacio de posibilidades. Las diferentes lenguas y modos de habla en un momento entran en primer plano, en otro se retiran, se mantienen separados o se combinan formando algo nuevo, pero de alguna manera siempre están ahí (Busch 2013: 31).

El repertorio es dinámico y se encuentra en permanente transformación, según los espacios comunicativos y la trayectoria biográfica de una persona, como señala Blommaert: "It is tied to an individual's life and it follows the peculiar biographical trajectory of the speaker. When a speaker moves from one social space into another, his or her repertoire is affected" (2008: 16).

El ejemplo de Rocío confirma esto: creció con el castellano y el gallego (considera los dos como sus lenguas maternas), fue aprendiendo y practicando el alemán en las temporadas que estuvo en Alemania (incluyendo competencias, por lo menos receptivas, de los dialectos sajón y bávaro), y ahora está ampliando sus competencias en inglés en Irlanda. Actualmente son el castellano y el inglés las lenguas que usa más en su vida cotidiana, en su trabajo y en sus relaciones de amistad. Se comunica diariamente con personas en Galicia (sobre todo con sus familiares), con las que habla mayormente en castellano (con algunas también en gallego o en un modo interlectal), además con su novio con el que habla francés.

Lengua y migración / Language and Migration 12:1 (2020) Monográfico, 13-37

Edición impresa: ISSN 1889-5425. Edición en línea: ISSN 2660-7166. @ Universidad de Alcalá 
Al mudarse a Irlanda el alemán quedó relegado a un segundo plano, pero sí sigue manteniendo contactos mediante las redes sociales en Internet.

Según la situación comunicativa y el interlocutor, una persona puede seleccionar o una o varias lenguas/variedades de su repertorio en una interacción, es decir, emplearlas de forma separada o conjunta hasta entrelazarlas en un modo de habla híbrido. La última forma, el language mixing -como Auer (1998) la denomina- no es un fenómeno reciente ni exclusivo de la transmigración. Ya se lo observó en muchas comunidades bilingües, sea en regiones históricamente bilingües, sea en contextos migratorios. Así, por ejemplo, Schmid (1994) descubrió que entre migrantes en la Suiza germanófona, que corresponden a la 'vieja' migración, se creyó una koiné neolatina, en la que se mezclan el español y el italiano.

Sin embargo, tales prácticas se vienen observando con más frecuencia en las sociedades actuales, las que -debido a la creciente diversidad de orígenes y rasgos que caracterizan a los migrantes- se han vuelto cada vez más complejas. Esta creciente complejidad y diversificación de formas sociales, culturales y lingüísticas ha generado el concepto de 'superdiversidad', introducido por Vertovec (2007) y acuñado por Blommaert en su Sociolingüística de la globalización (2010), reemplazando el paradigma multicultural y multilingüe en el sentido descrito arriba. Estas condiciones de superdiversidad fomentan prácticas pluri/translingües, al paso que propulsan la formación de grupos heterogéneos entremezclados en los llamados 'globalized neighbourhoods'. Como sostiene Blommaert (2010: 7), estos grupos combinan muchas veces elementos de diferentes lenguas migratorias en sus prácticas comunicativas, creando una especie de nuevas linguas francas.

Patzelt (2016,22 2018) demuestra esto en el caso de migrantes de diferentes países hispanoamericos (Perú, Colombia, Venezuela) y de Brasil en la Guayana Francesa que me debe servir aquí como último ejemplo. Las redes sociales de estos migrantes comprenden, por un lado, relaciones con sus respectivas sociedades de origen, con las que están en continuo contacto de manera real y/o virtual. Por otro lado, tienen múltiples contactos en la sociedad de acogida. Los migrantes que provienen de diferentes países hispanohablantes de Sudamérica suelen destacar que se comunican frecuentemente con brasileños, de manera que han desarrollado un repertorio lingüístico que es -por lo menos- trilingüe: español, portugués y francés. Tanto es así que en esta situación de contacto ha surgido el (auto)concepto 'sudamericano' que se define a base de rasgos comunes y similares (como situación social, culturas y lenguas parecidas). Como observa Patzelt, con esta autodeterminación se delimitan de los 'hispanos', un término que se asociona muchas veces con los migrantes provenientes de la República Dominicana. Los migrantes 'sudamericanos' se consideran integrados, no solo lingüísticamente, sino también 
en su papel de miembros autóctonos del continente sudamericano. Con esta construcción identitaria transgreden tanto las fronteras nacionales como las lingüísticas, apartándose de la correspondencia 1:1 entre un grupo étnico o un territorio nacional y su lengua. Integran elementos de distintos orígenes para crear algo propio y nuevo, una identidad diaspórica transnacional (Patzelt 2018: 139-140).

Esta se expresa y al mismo tiempo se construye mediante la combinación indexical de elementos lingüísticos, como Patzelt demuestra en base a una conversación entre una brasileña con su hija y su amiga colombiana [B = (madre) brasileña, $\mathrm{H}=$ su hija, $\mathrm{C}=$ amiga colombiana de $\mathrm{B}]$ :

(1) B: [...] E ele ele agora mesmo se jubilou, acho que ... ele foi com uma boa jubilação [...] falei ... eu falei com ele a Noite Boa [...]. (a su hija) Senta-te, ma chérie!

(2) C: Siéntate, chérie, ya va a empezar.

(3) H: Déjà? Ça commençe déjà, mami? (la madre no reacciona)

(4) C: Sí, empieza.

(5) H: Mami, empeça já?

(6) B: Senta-te, senta-te bem, chérie. [...] Regarde, el y a les touloulous ${ }^{23}$

(Patzelt 2016: 248, 2018: 142-143)

En el primer turno, la brasileña habla portugués con varias marcaciones translingües: se jubilon y jubilação, derivadas del español y adaptadas morfológicamente al portugués (en portugués sería aposentar-se y pensão), así como Noite Boa, un calco del español Nochebuena (Véspera de Natal en portugués). A la hija se dirige en portugués (Senta-te), pero utiliza la fórmula de tratamiento francesa ma chérie. En el último turno (6) de B se registra una alternacia de código del portugués al francés. La colombiana habla español con una inserción del francés (chérie) en el turno 2.

La hija de la brasileña interviene en francés (turno 3), cambiando al portugués en el turno 5. Al insertar empeça retoma el verbo empezar, utilizado por la colombiana en el turno anterior, parecido al portugués empecer, pero con otro significado (empecer $=$ poner obstáculos, perjudicar). ${ }^{24}$ Igualmente, el híbrido jubilação empleado por B resulta de que retoma la palabra jubilación que la colombiana ha utilizado poco antes, como aclara Patzelt. Por tanto, no son préstamos, sino creaciones espontáneas que emergen en un proceso dinámico en el que se negocian las identidades de manera flexible y situativa. Las dos mujeres afirman que la mezcla es la manera de hablar entre ellas. Se hace de manera consciente y es de índole indexical, es decir, mediante la mezcla marcan su pertenencia al grupo de los 'sudamericanos' y van construyendo su identidad diaspórica transnacional.

Lengua y migración / Language and Migration 12:1 (2020) Monográfico, 13-37

Edición impresa: ISSN 1889-5425. Edición en línea: ISSN 2660-7166. @ Universidad de Alcalá 


\section{Conclusión}

El análisis comparativo de los modelos de migración nos ha permitido arrojar luz sobre las distintas tendencias en el estudio de las dinámicas migratorias, de acuerdo con las condiciones correspondientes a cada período y su modelo predominante. Aunque, como se ha subrayado, algunos fenómenos que se observan actualmente no son totalmente nuevos, en las sociedades contemporáneas son más frecuentes y de carácter más intenso y complejo.

Resumiendo podemos constatar lo siguiente:

El modelo de e/inmigración, característico del período del paradigma nacional, fomentó la asimilación social y sociolingüística a la sociedad receptora, dándose con más velocidad en un entorno urbano, debido al carácter abierto de las redes sociales compuestas de personas de distintos orígenes. Además, se han identificado otros factores, como la ideología monolingüe de las sociedades receptoras y -específicamente en el caso de los gallegos en Argentina- la estigmatización de la lengua de origen.

El modelo de migración de retorno, correspondiente a la época del paradigma multicultural, favoreció la conservación de la lengua de origen, pero no la adquisición de la lengua de la sociedad receptora. En el repertorio lingüístico de los migrantes suele predominar la lengua de origen, por lo menos en la primera generación, lo que está en interrelación con sus redes sociales que comprenden mayormente relaciones con coterráneos, pero contactos limitados con personas de la sociedad local.

La orientación al retorno, adoptada tanto por los países de acogida como por los mismos migrantes, incentivó la separación. Sin embargo, hay migrantes que han optado por la integración como estrategia aculturativa y configuración identitaria. El caso de Inês ha ejemplificado esta opción, reflejada en la ampliación de su red social y en sus usos lingüísticos flexibles, y motivada en buena parte por su expectativa de permanecer en Alemania o circular entre Alemania y Portugal.

Finalmente, el modelo de transmigración contribuye, por lo general, a la integración social y sociolingüística en ambos lados, ya que los migrantes participan en actividades tanto en el país de residencia como en el lugar de origen. ${ }^{25}$ Además, ha generado redes sociales transnacionales, caracterizadas por la diversidad e intensidad de las relaciones que transgreden las fronteras nacionales. De este modo, se incentiva el desarrollo de un repertorio plurilingüe complejo y dinámico, que se emplea de manera flexible según el contexto social.

Entonces, ampliando la tipología de Berry, podemos añadir una orientación o estrategia más, que ya no se puede concebir de manera bipolar. Por tanto, me parece apropiado denominarla transcultural o 
transnacional. Según mi manera de ver, esta puede presentarse en dos variantes:

- o como una evolución continuada de la integración, en el sentido de que al integrar elementos de diferentes orígenes se abre el camino hacia un espacio transfronterizo que los transmigrantes constituyen a través de su práctica vivencial, construyendo identidades sociales con referencias múltiples, o sea identidades transnacionales y translingües;

- o bien como una orientación individual, un término que emplea Bourhis (2001) para referirse a una persona que no se siente vinculada profundamente ni a la cultura de origen ni a la de la sociedad de acogida. Rechaza fijaciones en términos de categorías étnicas o grupales, configurando su identidad de manera individual. Entonces, esta orientación se aproxima a lo que Marcia (1989) ha llamado identidad difusa, pero no en sentido de encontrarse en un conflicto entre diferentes afiliaciones, sino como una opción elegida conscientemente por la persona misma, que quiere seguir su propio camino.

Sin duda, estas opciones están ganando relevancia en la era de transmigración y superdiversidad que caracterizan nuestras sociedades contemporáneas.

Eva Gugenberger

Universidad Europea de Flensburg,

Seminario Románico

Recepción: 10/06/2019; Aceptación: 13/11/2019

\section{Notas}

1 Cabe señalar que Pries designa un cuarto tipo de migración, la diáspora, que en esta contribución no será tomada en consideración.

2 Cuando de aquí en adelante se habla de lengua de origen y lengua receptora, se incluye la posibilidad de que se trate de dos variedades del mismo idioma.

3 La distinción entre code-switching y language-mixing se basa en Auer (1998). Según su definición, el code-switching tiene una función discursiva que se puede interpretar localmente. En cambio, el language-mixing corresponde a una función global que está relacionada con una dimensión identitaria.

4 Para la perspectiva del migrante y en lo tocante a la dimensión lingüística me parece más apropiado el término oscilación.

5 Cabe mencionar que la mezcla de lenguas también se puede observar en el tipo integracionista. La diferencia está en el motivo que produce la mezcla. El tipo integracionista suele saber diferenciar las lenguas por su buena competencia en las dos, alterna entre ellas sin problema. Si emplea el mixing, lo hace de manera consciente marcando así su identidad bilingüe. En cambio, la oscilación se debe más bien a una actitud de indiferencia o apatía del migrante frente a su forma de hablar.

Lengua y migración / Language and Migration 12:1 (2020) Monográfico, 13-37

Edición impresa: ISSN 1889-5425. Edición en línea: ISSN 2660-7166. @ U Universidad de Alcalá 
6 En cuanto a la tercera estrategia, Berry especifica: separación concierne la postura de los migrantes, mientras que segregación se refiere a la actitud de la sociedad receptora.

7 Para más información, véase las notas en los diferentes ejemplos.

8 Milroy distingue las siguientes categorías (1980: 20-21; 49-52): Alta densidad significa que las personas con las que un individuo tiene relaciones, también están vinculadas entre ellas. En cambio, baja densidad se refiere al caso en el que las personas de la red del individuo no están interconectadas. Multiplejidad significa que dos personas están interrelacionadas de diferentes maneras (por ej. aldeanos, parientes, colegas de trabajo). En cambio, en el caso de uniplejidad la relación es de un solo tipo.

9 Los resultados presentados aquí forman parte de un estudio empírico más amplio llevado a cabo en Buenos Aires entre 1997 y 2000. Metodológicamente, el estudio está basado en entrevistas de tipo cualitativo en el que se combina un componente narrativo-biográfico y un componente centrado en temas sociolingüísticos, complementado por observación participativa. La muestra está compuesta por un total de 75 personas entrevistadas, que corresponden a cuatro grupos: 13 migrantes de la primera migración masiva, que llegaron en los años veinte y treinta del siglo pasado a Argentina, 24 migrantes de la segunda oleada migratoria en la época de posguerra (1948-1960) así como 38 personas de la segunda generación (18 de la primera, 20 de la segunda migración masiva).

10 Todos los nombres de los informantes han sido cambiados.

$11 \mathrm{E}=$ entrevistadora.

12 Los argentinismos están marcados en negrita, sh corresponde al žeísmo. Las versalitas marcan palabras gallegas (TES = segunda persona singular del verbo tener, XANTARES = comidas). Cabe mencionar que Beatriz es una de las personas entrevistadas que todavía hablan fluidamente el gallego, como demuestra en otras partes de la entrevista.

${ }^{13}$ Sin embargo, cabe señalar que resultados de investigaciones nunca son definitivos, como demuestra Reyna Muniain $(2015,2018)$ en un estudio reciente sobre el caso del gallego en Buenos Aires. En los últimos años han surgido iniciativas para la recuperación de la lengua gallega. Según Reyna Muniain (2015: 42), los dos factores cruciales que han incentivado esta nueva tendencia son: (1) una crisis general de la sociedad argentina, encadenada por la difícil situación económica y política, que incitó a muchos descendientes de migrantes a mirar hacia el país de sus antepasados, tomando en consideración una posible migración hacia allá; y (2) una crisis de identidad propia de los descendientes de gallegos, impulsada por la inminente desaparición del gallego debido a que los últimos hablantes nativos se están muriendo progresivamente.

Los nuevos impulsores del gallego suelen utilizar frecuentemente Internet como espacio de comunicación. Reyna Muniain (2015: 47) señala que una amplia mayoría de sus entrevistados indicó que empleaban el gallego con una alta frecuencia en sus comunicaciones por chat, sms y facebook con otros miembros de las redes de neohablantes. Además, las nuevas tecnologías les ofrece la posibilidad de estar en permanente contacto con familiares y amigos en Galicia, lo que también refortalece el vínculo con la lengua gallega.

${ }^{14} \mathrm{La}$ entrevista se realizó en el marco de un estudio piloto mío sobre migrantes provenientes de diferentes regiones de la Península Ibérica en Alemania. Así como en el estudio sobre los gallegos en Argentina, el método utilizado para proporcionar los datos es una combinación de dos variantes de entrevista, una narrativa y otra centrada en temas, lo cual permite guiar hasta cierto grado el transcurro de la entrevista y al mismo tiempo dar lugar a los entrevistados a aportar temas y aspectos no previstos que puedan ser relevantes (Schlehe 2003: 77-78).

${ }^{15}$ El concepto de repertorio lingüístico se concibe como el conjunto de todas las habilidades lingüísticas, si bien su grado suele variar y aunque sean parciales o 'truncadas' (Blommaert 2010: 103, Blommaert/Backus 2011: 8); más adelante volveré sobre este concepto. En este sentido, tanto Inês como Manuel disponen de un repertorio multilingüe, si bien en el caso de Manuel el alemán es de índole más truncada.

${ }^{16}$ Hay varios términos en castellano que están circulando en los discursos académicos para referirse al fenómeno: hibridez, hibrididad, hibridación e hibridización.

Lengua y migración / Language and Migration 12:1 (2020) Monográfico, 13-37 Edición impresa: ISSN 1889-5425. Edición en línea: ISSN 2660-7166. @ Universidad de Alcalá 
Hibrididad se ha formado en base al modelo inglés o alemán (bibridity, Hybridität); bibridación es el término que utiliza García Canclini, destacado filósofo y antropólogo argentino, en su conocido libro Culturas híbridas (1990).

17 Así, por ejemplo, el criollista Whinnon (1971: 110) utiliza, en analogía a la biología, linguistic hybridization como hiperónimo para el fenómeno de mezcla de lenguas. La denominación 'híbrido' o 'formas híbridas' se viene aplicando desde hace tiempo para el cruce de morfemas de distintos orígenes lingüísticos.

${ }^{18}$ Véase por ejemplo Bronfen/ Marius/ Steffen (1997).

19 Tradicionalmente, el término llevaba una connotación negativa (véase Ha 2005).

${ }^{20}$ La entrevista con Rocío fue llevada a cabo y analizada por Michelle Griszbacher en el marco de un trabajo de seminario en la universidad de Leipzig (2018).

${ }^{21}$ Cabe destacar que el paradigma de hibridación lingüística constituye una perspectiva de investigación, introducida en las últimas décadas, mayormente en estudios sobre procesos lingüísticos en el contexto migratorio (por ej. Erfurt 2003, Hinnenkamp/ Meng 2005, Gugenberger 2010a, 2018), a fin de apartarse de modelos dicotómicos. Sin embargo, es igualmente aplicable a casos anteriores, como yo también he mostrado en mi estudio sobre los gallegos en Buenos Aires, al conjugar el concepto de hibridación con la tipología de Berry (Gugenberger 2007, 2018: 127 y ss.). A mi manera de ver, la ventaja de reunir los dos enfoques reside en lo siguiente: el concepto de hibridación no puede renunciar del todo al supuesto de polos opuestos como marco de referencia, tal como lo ofrece el modelo de Berry, para poder hablar de hibridación. Si bien los opuestos pueden anularse desembocando en un espacio híbrido, para poder analizar este espacio también son necesarios momentos de diferencia y de divergencia. Pero una perspectiva hibridista permite distanciarse de concepciones de sistemas monolíticos 'puros', abriendo el camino hacia la transgresión de fronteras y la innovación.

${ }^{22}$ El estudio de Patzelt, realizado a base de cuestionarios, entrevistas cualitativas y grabaciones, comprende un total de 330 informantes de distintos orígenes, incluyendo países caribeños y sudamericanos.

${ }^{23}$ Figuras de mujeres típicas del Carnaval.

${ }^{24}$ Patzelt indica que, sobre todo en conversaciones de migrantes iberoamericanos de la segunda generación, se utilizan muchas palabras que existen tanto en español como en portugués, pero con sentido distinto. Según la autora, es una estrategia para crear identidades lingüísticas dentro de un determinado grupo de hablantes mediante un código 'secreto' que solo se emplea dentro del grupo respectivo (2017: 250).

${ }^{25}$ Una excepción a este respecto pueden constituir los expatriados que trabajan en empresas transnacionales. En caso de que estos se muevan casi exclusivamente en la comunidad de expatriados, cuya lengua de comunicación suele ser una lingua franca (frecuentemente el inglés) distinta a la de la sociedad receptora, no llegan a integrarse ni social ni sociolingüísticamente en el país donde residen, en general, por un período limitado (Bürki 2017). Además, dada la creciente importancia del inglés como medio de comunicación, no solo en el caso específico de comunidades de expatriados, sino también en otros contextos, incluso en interacciones entre hablantes de distintos orígenes lingüísticos y personas de la sociedad local, sería interesante investigar hasta qué grado el avance del inglés como lingua franca influye negativamente en la adquisición de la lengua local.

\section{Referencias bibliográficas}

Andrade-Eeckhoff, Katharine y Claudia Marina Silva Ávalos. 2004. "La globalización de la periferia: flujos transnacionales migratorios y el tejido socio-productivo local en América Central". Revista Centroamericana de Ciencias Sociales, 1. 57-86.

Lengua y migración / Language and Migration 12:1 (2020) Monográfico, 13-37 Edición impresa: ISSN 1889-5425. Edición en línea: ISSN 2660-7166. @ Universidad de Alcalá 
Auer, Peter. 1998. "From Code-Switching via Language Mixing to Fused Lects: Toward a Dynamic Typology of Bilingual Speech". InLiSt - Interaction and Linguistic Structures, 6. URL: http://www.ub.uni-konstanz.de/ kops/volltexte/2000/470/

Berry, John. 1996. “Acculturation and Psychological Adaptation”. En Migration Ethnizität - Konflikt: Systemfragen und Fallstudien, Klaus Bade (ed.), 171-186. Osnabrück: Universitätsverlag.

Bhabha, Homi K. 1994. The location of culture. London et al.: Routledge.

Bhabha, Homi K. 1997. "Verortungen der Kultur". En Hybride Kulturen. Beiträge zur anglo-amerikanischen Multikulturalismusdebatte, Elisabeth Bronfen, Benjamin Marius y Therese Steffen (eds.), 123-148. Tübingen: Stauffenberg.

Bierbach, Christine y Gabriele Birken-Silverman. 2003. "Italienische und spanische Migranten in Südwestdeutschland: 'Vicini, ma diferentes'”. En Mehrsprachigkeit und Migration, Jürgen Erfurt, Gabriele Budach y Sabine Hofmann (eds.), 77-99. Frankfurt am Main et al.: Lang.

Blommaeart, Jan. 2008. "Language, asylum and the national order". Current Anthropology, 50/4. 415-441.

Blommaeart, Jan. 2010. The Sociolinguistics of Globalization. Cambridge: Cambridge University Press.

Blommaert, Jan y Ad Backus. 2011. “Repertoires revisited: 'Knowing language' in Superdiversity". Working Papers in Urban Language E Literacies, WP 67, 1-26. Tilburg University.

Bourhis, Richard. 2001. "Acculturation, language maintenance, and language shift”. En Theories on Maintenance and Loss of Minority Languages: Towards a more integrated explanatory framework, Jetske Klatter-Folmer y Piet Van Avermaet (eds.), 5-37. Münster et al.: Waxmann.

Bossong, Georg. 2009. "Suiza: identidades lingüísticas complejas en un país plurilingüe”. En Migración y exilio españoles en el siglo XX, Luis Calvo Salgado et al. (eds.), 69-79. Madrid/Frankfurt am Main: Iberoamericana/Vervuert.

Bronfen, Elisabeth, Benjamin Marius y Therese Steffen (eds.). 1997. Hybride Kulturen. Beiträge zur anglo-amerikanischen Multikulturalismusdebatte. Tübingen: Stauffenberg.

Busch, Brigitta. 2013. Mehrsprachigkeit. Wien: Facultas.

Bürki, Yvette. 2017. "Migración y lengua. La importancia de la perspectiva glotopolítica”. Ponencia en el Tercer Congreso Latinoamericano de Glotopolitica. Reflexiones desde y hacia América y Europa. Hannover, el 27 - 30 de septiembre de 2017.

Erfurt, Jürgen. 2003. "'Multisprech': Migration und Hybridisierung und ihre Folgen für die Sprachwissenschaft”. En “Multisprech”: Hybridität, Variation, Identität, Jürgen Erfurt (ed.). OBST (Osnabrücker Beiträge zur Sprachtheorie) 65. 5-33.

Erfurt, Jürgen. 2005. “'de meme I hope j’te bother pas': Transkulturalität und Hybridität in der Frankophonie”. En Transkulturalität und Hybridität. L'espace francophone als Grenzerfahrung des Sprechens und Schreibens, Jürgen Erfurt (ed.), 9-36. Frankfurt am Main et al.: Lang.

Estévez Grossi, Marta. 2018. Lingüistica migratoria e interpretación en los servicios públicos. La comunidad gallega en Alemania. Berlin: Frank \& Timme.

García Canclini, Nestor. 1990. Culturas híbridas. Estrategias para entrar y salir de la modernidad. México D.F.: Grijalbo.

Garza-Guerrero, César. 1974. "Culture Shock. Its mourning and the vicissitudes of Identity”. Journal of American Psychoanalytic Association, 22/1. 408-429.

Glick Schiller, Nina, Linda Basch y Cristina Szanton Blanc. 1995. "From Immigrant to Transmigrant: Theorizing Transnational Migration”. Anthropological Quarterly, 68/1. 48-63

Griszbacher, Michelle. 2018. Das Modell der Transmigration - Eine Analyse der Wanderbewegungen zwischen Deutschland und Spanien und deren sprachlichen Auswirkungen anhand eines biographisch-narrativen Interviews. Trabajo de seminario, Universidad de Leipzig.

Lengua y migración / Language and Migration 12:1 (2020) Monográfico, 13-37 Edición impresa: ISSN 1889-5425. Edición en línea: ISSN 2660-7166. C U Universidad de Alcalá 
Gugenberger, Eva. 2007. “Aculturación e hibrididad lingüísticas en la migración. Propuesta de un modelo teórico-analítico para la lingüística de la migración”. Revista Internacional de Lingüistica Iberoamericana (RILI), V/2 (10). 21-45.

Gugenberger, Eva. 2010a. "Das Konzept der Hybridität in der Migrationslinguistik”. En Tout-Monde: Interkulturalität, Hybridisierung, Kreolisierung. Kommunikations- und gesellschaftstheoretische Modelle zwischen “alten” und “neuen” Räumen, Ralph Ludwig y Dorothee Röseberg (eds.), 67-91. Frankfurt am Main et al.: Lang.

Gugenberger, Eva. 2010b. "Von der Interferenz zur Hybridität: Bemerkungen zur Terminologie und zum Paradigmenwechsel in der Sprachkontaktforschung”. En Sprachen - Sprechen - Schreiben. Blicke auf Mebrsprachigkeit, Peter Cichon et al. (eds.), 26-53.Wien: Praesens.

Gugenberger, Eva. 2018. Theorie und Empirie der Migrationslinguistik. Mit einer Studie $z u$ den Galiciern und Galicierinnen in Argentinien. Wien et al.: LIT.

Gugenberger, Eva y Clare Mar-Molinero. 2018. “Introducción”. Migración de retorno y migración transnacional en, desde y hacia el espacio iberorrománico. Sección temática de la Revista Internacional de Lingüística Iberoamericana (RILI), XVI/31. 7-12.

Gumperz, John. 1964. "Linguistic and Social Interaction in Two Communities". American Anthropologist, 66. 137-153.

Gumperz, John. 1982. Discourse Strategies. Cambridge: Cambridge University Press.

Ha, Kien Nghi. 2005. Hype um Hybridität. Kultureller Differenzkonsum und postmoderne Verwertungstechniken im Spätkapitalismus. Bielefeld: transcript.

Han, Petrus. 2010. Soziologie der Migration. Constanza: UVK Verlagsgesellschaft.

Hinnenkamp, Volker y Katharina Meng (eds.). 2005. Sprachgrenzen überspringen. Sprachliche Hybridität und polykulturelles Selbstverständnis. Tübingen: Narr.

Le Page, Robert y Andrée Tabouret-Keller. 1985. Acts of Identity. Creole based approaches to language and ethnicity. Cambridge: Cambridge University Press.

Lüdi, Georges. 2003. "Mehrsprachige Repertoires und plurielle Identität von Migranten: Chancen und Probleme”. En Plurilingualität und Identität: Zur Selbst- und Fremdwabrnebmung mehrsprachiger Menschen, Inez de Florio-Hansen y Adelheid $\mathrm{Hu}$ (eds.), 39-58. Tübingen: Stauffenburg.

Mar-Molinero, Clare. 2018. "Language issues for US-raised 'returnees' in Mexico". En The Handbook of Spanish as a heritage/minority language, Kim Potowski (ed.), 555568. London/New York: Routledge.

Marcia, James. 1989. "Identity diffusion differentiated". En Psychological development across the life-span, Mary Luszcz y Ted Nettelbeck (eds.), 289-295. Amsterdam et al.: Elsevier.

Middell, Katharina/Middell, Matthias. 1998. "Migration als Forschungsfeld". Grenzgänge, 5/9. 6-23.

Milroy, Lesley. 1980. Language and social networks. Oxford: Blackwell.

Muñoz Sánchez, Antonio. 2012. "Una introducción a la historia de la emigración española en la República Federal de Alemania (1960-1980)”. Iberoamericana, XII/46. 23-42. http://www.iai.spkberlin.de/fileadmin/dokumentenbibliothek/Iberoamericana/462012/46_Munoz_Sanchez.pdf.

Oksaar, Els. 2003. Zweitspracherwerb. Wege zur Mebrsprachigkeit und zur interkulturellen Verständigung. Stuttgart: Kohlhammer.

Patzelt, Carolin. 2016. Sprachdynamiken in modernen Migrationsgesellschaften. Romanische Sprachen und romanisch-basierte Kreolsprachen in FranzösischGuayana. Stuttgart: Steiner.

Patzelt, Carolin. 2017. "Plurilingüismo e hibridación como recursos de indexicalidad social: dinámicas lingüísticas en contextos diaspóricos”. En Variación y cambio lingüistico en situaciones de contacto, Azucena Palacios (ed.), 237-255. Madrid/Frankfurt am Main: Iberoamericana/Vervuert.

Patzelt, Carolin, 2018. "Identidades transnacionales y repertorios plurilingües: migrantes iberorrománicos en la Guayana Francesa”. Revista Internacional de Lingüística Iberoamericana (RILI), XV/1 (31). 123-148.

Lengua y migración / Language and Migration 12:1 (2020) Monográfico, 13-37

Edición impresa: ISSN 1889-5425. Edición en línea: ISSN 2660-7166. @C Universidad de Alcalá 
Pries, Ludger. 2000. “'Transmigranten’ als Typ von Arbeitswanderern in plurilokalen sozialen Räumen”. En Migration, gesellschaftliche Differenzierung und Bildung: Resultate des Forschungsschwerpunktprogramms FABER, Ingrid Gogolin y Bernhard Nauck (eds.), 415-438. Opladen: Leske + Budrich.

Pries, Ludger. 2008. Die Transnationalisierung der sozialen Welt: Sozialräume jenseits von Nationalgesellschaften. Frankfurt am Main: Suhrkamp.

Reyna Muniain, Facundo. 2015. "Lingua, cultura e identidade: estratexias de aculturación e reculturación na colectividade galega de Bos Aires”. GRIAL, 53/206. 38-45.

Reyna Muniain, Facundo. 2018. "Política lingüística familiar en contexto de diáspora. Lengua e identidad en la comunidad gallega de Buenos Aires". En Migración y contacto de lenguas en la Romania del siglo XXI / Migration et contact de langues au $X X I^{e}$ siècle, Carolin Patzelt, Katrin Mutz, y Carolin Spiegel (eds.), 295-321. Frankfurt am Main et al: : Peter Lang.

Schlehe, Judith. 2003. "Formen qualitativer ethnographischer Interviews". En Methoden und Techniken der Feldforschung, Bettina Beer (ed.), 71-93. Berlin: Reimer.

Schmid, Stephan. 1994. L'italiano degli spagnoli: Interlingue di immigrati nella Svizzera tedesca. Milano: F. Angeli.

Schneider, Irmela y Christian W. Thomsen (eds.). 1997. Hybridkultur. Medien, Netze, Künste. Köln: Wienand.

Silverstein, Michael. 2003. "Indexical order and the dialectics of social life". Language and Communication, 23. 193-229.

Vertovec, Steven. 2007. "Super-diversity and its implications". Ethnic and Racial Studies 30/6. 1024-1054.

Welsch, Wolfgang. 1997. “Transkulturalität. Zur veränderten Verfassung heutiger Kulturen”. En Hybridkultur. Medien, Netze, Künste, Irmela Schneider y Christian W. Thomsen (eds.), 67-89. Köln: Wienand.

Whinnon, Keith. 1971. "Linguistic hybridization and the 'special case' of pidgins and creoles”. En Pidginization and Creolization of Languages, Dell Hymes (ed.), 91-116. Cambridge: Cambridge University Press.

Lengua y migración / Language and Migration 12:1 (2020) Monográfico, 13-37 Edición impresa: ISSN 1889-5425. Edición en línea: ISSN 2660-7166. C Universidad de Alcalá 